\title{
KAJIAN PERILAKU ADAPTASI PETANI MANGGA TERHADAP PERUBAHAN IKLIM DI KECAMATAN PANYINGKIRAN KABUPATEN MAJALENGKA
}

\author{
GILANGSARI ROSALINA PUTRI, DHANY ESPERANZA \\ Departemen Sosial Ekonomi Pertanian, Program Studi Agribisnis, Fakultas Pertanian, \\ Universitas Padjadjaran \\ *Email: gilangsarirp@gmail.com
}

\begin{abstract}
ABSTRAK
Perubahan iklim yang terjadi dan semakin buruk selama beberapa tahun ke belakang sangat mempengaruhi kegiatan agribisnis komoditas pertanian. Mangga, sebagai salah satu komoditas buah-buahan unggulan Indonesia, juga sangat dipengaruhi oleh perubahan iklim. Produktivitas mangga seringkali menurun karena kondisi iklim yang tidak mendukung. Fenomena perubahan iklim ini kemudian menimbulkan perilaku adaptasi dari petani mangga dalam rangka mempertahankan usahatani mangga karena perubahan iklim diprediksi akan terus berlangsung hingga periode waktu yang tidak dapat ditentukan. Penelitian ini bertujuan untuk menggambarkan perilaku adaptasi petani mangga akibat perubahan iklim dengan causal loop diagram. Desain penelitian yang digunakan adalah deskriptif kualitatif dengan proses analisis data bertumpu pada penggunaan system thinking melalui penggambaran causal loop diagram. Hasil penelitian menunjukkan bahwa perilaku adaptasi petani mangga terbentuk dari 20 variabel yaitu curah hujan, luas lahan, jumlah pohon, produksi mangga, ketersediaan mangga, mangga berkualitas, harga mangga, permintaan, penerimaan, pendapatan, alokasi uang untuk pembelian sarana produksi dan input pertanian, sarana produksi dan input pertanian, produktivitas pohon mangga, penggunaan ZPT, daya tahan pohon, serangan OPT, penggunaan pestisida, perawatan pohon, biaya perawatan, dan biaya produksi. Variabel perawatan pohon menjadi leverege point karena memiliki pengaruh terbanyak terhadap keseluruhan sistem dibanding dengan variabel lain.
\end{abstract}

Kata kunci: Perubahan Iklim, Adaptasi, Petani Mangga, Causal Loop Diagram

\section{ABSTRACT}

Climate change has been indicated getting worse in the last couple of years and suspected for its influence in agribusiness activity. Mango, as one of superior Indonesian fruit is impacted by this phenomenon. Mango productivity has been fluctuating in declining trend under highly unpredictive climate condition. This natural phenomenon leads to adaptation behavior of mango farmer in order to maintain their business, because climate change is predicted to continue for uncertain period of time. The purpose of this research is to describe the behavior of mango farmer due to climate change using causal loop diagram. The design of this research is qualitative descriptive by analysing data of the process of archetypes and causal loop diagram. Results show that the farmer's adaptation behavior was made up of 20 variables which are rainfall, land area, number of mango trees, production of mango, stock of mango, mangoes with the good quality, mango price, demand of mango, money reception, income, allocation of money for the purchase of inputs and agricultural inputs, means of production and agricultural inputs, productivity of mango trees, use of growth regulators, tree endurance, pests attack, use of pesticides, care of trees, maintenance costs, and production costs. Tree care variables become leverage point for having the most influence on the whole system compared to the other variables.

Keywords: Climate Change, Adaptation, Mango Farmer, Causal Loop Diagram 


\section{PENDAHULUAN}

Sebagai negara agraris, Indonesia menjadi sangat bergantung terhadap iklim. Fenomena perubahan iklim sebagai akibat dari pemanasan global berdampak pada kenaikan frekuensi dan intensitas kejadian cuaca ekstrem, perubahan pola curah hujan, serta peningkatan suhu udara dan permukaan air laut (IPCC, 2007; Surmaini, Runtunuwu, dan Las, 2011).

Di Indonesia, perubahan iklim terindikasi oleh peningkatan frekuensi banjir dan kekeringan yang diasosiasikan dengan fenomena El Nino Southern Oscillation (ENSO). Fenomena ENSO sangat mempengaruhi distribusi curah hujan sehingga terjadi El Nino yang diidentifikasi dengan kemarau panjang dan La Nina dengan peningkatan curah hujan di atas normal sehingga menyebabkan banjir di beberapa wilayah (Handayani, Sulistyono, Budyatmodjo, dan Subekti, 2015). Suhu maksimum dan minimum di 33 provinsi di Indonesia pun meningkat secara konsisten dari tahun 1980-2002 (Boer dan Suharnoto, 2012). Dalam National Action Plan for Climate Change Adaptation (RAN-API) disebutkan bahwa perubahan iklim semacam ini dapat berdampak besar terhadap banyak sektor penting seperti sektor pertanian, kehutanan, perikanan, kesehatan, area pesisir, dan sumberdaya air (Bappenas, 2012).

Sektor pertanian, dengan risiko yang besar akibat perubahan iklim, tetap menjadi penyumbang Produk Domestik Bruto (PDB) terbesar kedua di Indonesia setelah sektor industri. Dari besaran kontribusi sektor pertanian tersebut, terdapat sumbangan subsektor hortikultura sebesar 1,52\% (BPS, 2018).

\section{Mangga (Mangifera indica L.)} adalah komoditas buah-buahan unggulan tahunan nasional dengan total jumlah produksi terbanyak ketiga di Indonesia (BPS, 2018). Provinsi Jawa Barat merupakan salah satu wilayah andalan pengembangan mangga di Indonesia yang memberikan kontribusi tertinggi ketiga setelah Provinsi Jawa Timur dan Jawa Tengah (Direktorat Jenderal Hortikultura Kementerian Pertanian, 2014). Produksi buah mangga di Jawa Barat dihasilkan dari daerah Indramayu, Cirebon, Majalengka, Kuningan, dan Sumedang (Ramadhani dan Rasmikayati, 2017). Kecamatan Panyingkiran adalah salah satu kecamatan di Kabupaten Majalengka dengan jumlah produksi mangga tertinggi hampir di setiap tahunnya. Rincian luas tanaman, luas panen, dan jumlah produksi mangga di Kecamatan Panyingkiran 
selama tahun 2011-2016 disajikan dalam Tabel 1.

Tabel 1. Luas Tanaman, Luas Panen, dan Produksi Mangga di Kecamatan Panyingkiran Tahun 2012-2016

\begin{tabular}{cccc}
\hline Tahun & $\begin{array}{c}\text { Luas } \\
\text { Tanaman } \\
\text { (Ha) }\end{array}$ & $\begin{array}{c}\text { Luas } \\
\text { Panen } \\
\text { (Ha) }\end{array}$ & $\begin{array}{c}\text { Produksi } \\
\text { (Ton) }\end{array}$ \\
\hline 2012 & $1.835,21$ & $1.820,21$ & $11.885,10$ \\
2013 & $1.845,21$ & $1.820,21$ & 479,80 \\
2014 & $1.854,61$ & $1.733,30$ & $19.182,00$ \\
2015 & $1.863,61$ & $3.850,00$ & $24.641,20$ \\
2016 & $1.876,01$ & $1.270,00$ & $14.288,00$ \\
\hline Sumber: BPS Kabupaten Majalengka, 2017
\end{tabular}

Berdasarkan Tabel 1, dapat dilihat bahwa luas tanaman mangga di Kecamatan Panyingkiran mengalami peningkatan setiap tahunnya, sedangkan jumlah produksinya berfluktuasi secara signifikan dari tahun ke tahun. Iklim, sebagai salah satu faktor yang sangat berdampak pada bidang pertanian, memiliki andil dalam tren jumlah produksi mangga yang berfluktuasi ini.

Salah satu komponen iklim yang dirasa dapat mempengaruhi produksi mangga secara langsung oleh petani adalah hujan. Hujan merupakan salah satu bentuk presipitasi dari atmosfer yang berwujud cairan, terbentuk dari kondensasi uap air di atmosfer menjadi butiran air yang cukup berat untuk jatuh ke daratan (Prawaka, 2016). Indikator perubahan iklim berkenaan dengan hujan yang berdampak langsung pada kegiatan usahatani mangga adalah besaran curah hujan dan perubahan pola curah hujan. Curah hujan yaitu ketinggian air hujan dalam tempat yang datar, tidak menguap, tidak meresap, dan tidak mengalir. Curah hujan yang dinyatakan sebesar $1 \mathrm{~mm}$ memiliki makna bahwa dalam luasan satu meter persegi pada tempat yang datar, tertampung air setinggi $1 \mathrm{~mm}$. Banyaknya curah hujan per satuan jangka waktu tertentu disebut intensitas hujan. Intensitas hujan yang besar berpotensi merugikan bidang pertanian, bahkan dapat menimbulkan bencana alam (Wicaksana, 2015).

Adaptasi merupakan salah satu upaya untuk meminimalisir potensi risiko terkait perubahan iklim (Adger et al, 2003). Saat ini, perubahan iklim mendorong petani mangga untuk lebih dinamis dalam melakukan adaptasi/penyesuaian kegiatan pertaniannya dengan kondisi iklim untuk meminimalisasi resiko tersebut. Adaptasi juga dilakukan oleh pelaku usahatani mangga guna mempertahankan dan meningkatkan produksinya. Penelitian ini bertujuan untuk mengetahui gambaran perilaku adaptasi petani mangga di Kecamatan Panyingkiran berdasarkan interaksi antar faktor yang mempengaruhinya. 


\section{METODE PENELITIAN}

Objek penelitian ini adalah perilaku adaptasi petani mangga terhadap perubahan iklim. Penelitian dilakukan di Kecamatan Panyingkiran, Kabupaten Majalengka. Penelitian ini menggunakan desain kualitatif dengan proses analisis data bertumpu pada penggunaan system thinking dengan penggambaran causal loop diagram. Metode yang digunakan dalam penelitian ini adalah metode studi kasus.

Sumber data yang digunakan dalam penelitian ini berupa data primer dan data sekunder. Data primer adalah data yang diperoleh dengan melakukan pengamatan langsung kepada objek penelitian. Sumber data primer berasal dari petani mangga di Kecamatan Panyingkiran, Kabupaten Majalengka. Data sekunder adalah data yang diperoleh melalui bahan bacaan atau literatur lainnya.

Penentuan informan dalam penelitian ini menggunakan teknik purposive sampling dengan kriteria informan kunci yaitu petani mangga, dengan status kepemilikan lahan sebagai pemilik/penggarap/pemilik dan penggarap. Pengumpulan data dilakukan dengan teknik triangulasi. Teknik triangulasi merupakan teknik pengumpulan data yang bersifat menggabungkan berbagai teknik pengumpulan data dan sumber data yang telah ada. Teknik triangulasi digunakan untuk meningkatkan pemahaman peneliti mengenai fenomena yang ditemukan. Teknik ini mengumpulkan sekaligus menguji kredibilitas data (Sugiyono, 2017).

\section{PEMBAHASAN}

Petani mangga di Kecamatan Panyingkiran menyadari bahwa telah terjadi perubahan iklim yang berpengaruh terhadap produksi tanaman mangga selama beberapa tahun terakhir. Indikator terjadinya perubahan iklim yang dirasakan langsung oleh petani adalah pergeseran pergantian musim. Intensitas hujan seringkali masih tinggi di pertengahan tahun, sehingga tanaman mangga yang seharusnya mulai berbunga menjadi terhambat pembungaannya dan mengalami rontok bunga.

Terjadinya perubahan iklim ini tidak dapat dihindari oleh petani. Mayoritas petani baru menyadari bahwa pergantian musim tidak berjalan sebagaimana biasanya ketika kekurangan atau kelebihan intensitas hujan sudah terjadi. Pergeseran musim yang tidak signifikan sudah dianggap biasa dan bukan merupakan suatu masalah besar karena 
para petani tersebut percaya bahwa segala yang berkaitan dengan iklim adalah kehendak Tuhan yang tidak dapat mereka ubah. Perubahan iklim bagaimanapun berdampak pada produksi tanaman mangga. Terlalu banyak hujan akan menyebabkan kerontokan pada bunga dan kebusukan pada buah. Udara yang lembab juga mengakibatkan peningkatan serangan hama dan penyakit pada tanaman mangga, sementara kekurangan air dapat membuat proses pembungaan dan pembuahan menjadi tidak maksimal.

Perilaku petani yang timbul sebagai respon dari terjadinya perubahan iklim tersebut adalah dengan beradaptasi. Adaptasi dilakukan oleh petani dalam berbagai cara, tujuannya yaitu untuk dapat bertahan menghadapi perubahan iklim dan meminimalisir resiko yang mungkin terjadi pada periode tanam selanjutnya. Bentuk perilaku adaptasi petani mangga ini dipengaruhi oleh faktor-faktor yang saling terkoneksi satu sama lain dalam hubungan sebab-akibat. Faktor-faktor tersebut kemudian dibuat menjadi variabel untuk dipetakan dengan causal loop diagram.

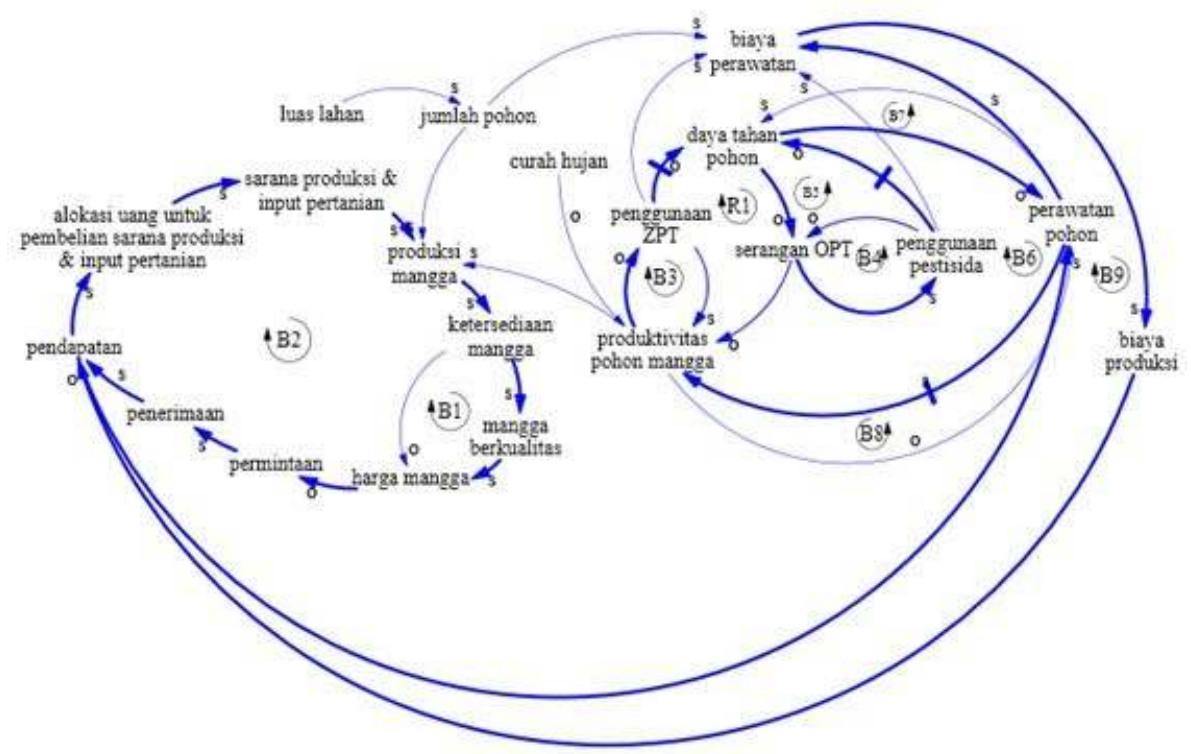

Gambar 1. Causal Loop Diagram Adaptasi Petani Mangga 
Curah hujan, sebagai indikator perubahan iklim yang paling dirasakan oleh petani, berpengaruh secara negatif terhadap produktivitas mangga. Tingginya curah hujan yang turun akan menurunkan produktivitas pohon mangga. Hal ini terjadi karena mangga merupakan tanaman yang tumbuh lebih baik dalam kondisi kering dan sedikit hujan.

Produktivitas pohon mangga kemudian berpengaruh terhadap produksi mangga. Semakin baik produktivitas pohon, semakin tinggi pula produksinya. Selain produktivitas pohon, besaran hasil produksi mangga yang dihasilkan petani setiap tahunnya juga sangat dipengaruhi oleh luas lahan dan jumlah pohon yang dimiliki dan atau digarap oleh petani tersebut. Kebanyakan petani memiliki lahan atau

pohon mangga hasil dari warisan orangtuanya.

Produksi mangga pada tahun tertentu akan menentukan ketersediaan mangga pada tahun yang sama. Semakin banyak buah mangga yang diproduksi, semakin besar kemungkinan tersedianya buah mangga dengan kualitas baik. Kualitas buah mangga kemudian akan menentukan harga pasar yang berlaku untuk mangga tersebut. Semakin baik kualitasnya, semakin tinggi pula harga jualnya (Loop B1). Di sisi lain, peningkatan kuantitas hasil produksi mangga akan menurunkan harga jual mangga tersebut (Loop B2). Semakin banyak kuantitas sebuah produk maka akan menurun harga jualnya di pasaran. Hal ini dapat dilihat dari perbedaan harga mangga saat off-season dan saat panen raya. Pada saat off-season, harga mangga gedong yang matang dari petani ke bandar berkisar Rp 30.000/kg, mangga gedong yang masih mentah Rp 15.000/kg, sedangkan saat panen raya harganya hanya setengah daripada itu.

Petani mangga tidak dapat begitu saja menaikkan harga mangga hanya karena mereka merasa bahwa biaya produksi yang mereka keluarkan lebih besar daripada biasanya. Jika petani serta merta menaikkan harga, maka permintaan terhadap mangga yang mereka jual akan berkurang (Loop B1 dan B2). Bandar atau pengumpul yang biasa membeli mangga dari petani tidak akan bersedia membeli mangga dari petani yang menjual dengan harga lebih tinggi. Akibatnya, petani tidak memiliki pasar untuk menjual mangga yang ia produksi. Oleh karena itu, menaikkan harga mangga secara sepihak oleh petani bukanlah hal yang baik, kecuali jika dilakukan secara serempak 
oleh semua petani karena biaya input pertanian yang semakin mahal.

Harga akan menentukan besarnya permintaan pada produk tersebut. Seperti pada teori permintaan dan penawaran, semakin rendah harga jual suatu barang maka akan semakin tinggi permintaan terhadap barang tersebut. Besaran permintaan terhadap mangga kemudian akan berpengaruh pada besaran penerimaan dan pendapatan yang diterima oleh petani mangga. Keuntungan dari pendapatan tersebut digunakan petani untuk memenuhi kebutuhan hidup keluarganya, sedangkan sisa pendapatannya akan dialokasikan untuk membeli sarana produksi dan input pertanian sehingga usahatani mangga sebagai penghidupan mereka dapat berlangsung secara berkelanjutan (Loop B1 dan B2).

Rendahnya produktivitas pohon mangga memicu peningkatan penggunaan ZPT oleh petani (Loop B3). Penggunaan ZPT seringkali dianggap sebagai jalan keluar yang instan dalam menghadapi pohon mangga yang tidak berproduksi secara maksimal. Hal ini kemudian terus dipercayai oleh mayoritas petani karena pada kenyataannya produksi mangga petani meningkat dan menjadi lebih baik saat petani menggunakan ZPT jika dibandingkan dengan saat petani tidak menggunakan ZPT. Namun, penggunaan ZPT secara berlebihan dalam jangka panjang membuat pohon menjadi jenuh dan overdosis. Akibatnya, daya tahan pohon mangga berkurang. Pohon menjadi mudah terserang penyakit dan kualitas buah yang dihasilkan dari pohon tersebut menjadi tidak optimal (Loop R1).

Pola perilaku seperti itu terus berlanjut sampai petani menyadari bahwa perilaku tersebut telah menimbulkan suatu masalah. Pohon mangga yang daya tahannya lemah harus diperhatikan dan dirawat secara lebih intensif oleh petani. Daya tahan pohon yang lemah menyebabkan pohon lebih mudah terserang hama dan penyakit. Serangan OPT ini kemudian berpengaruh secara positif terhadap penggunaan pestisida oleh petani. Semakin banyak OPT yang menyerang tanaman, semakin banyak pula dosis dan jenis pestisida yang digunakan oleh petani. Ironisnya, penggunaan pestisida secara terus-menerus dalam jangka waktu yang lama akan berimbas pada penurunan daya tahan pohon itu sendiri (Loop B4 dan B5).

Munculnya variabel perawatan pohon membentuk interaksi baru dengan variabel daya tahan pohon dan variabel produktivitas mangga (Loop B6, B7 dan 
B8). Semakin sering perawatan pohon dilakukan, semakin baik pula daya tahan pohon mangga. Sayangnya, petani seringkali mengabaikan perawatan pohon ketika daya tahan pohon mangga dianggap masih baik (Loop B7). Hal ini juga terjadi pada produktivitas pohon mangga. Semakin sering perawatan pohon dilakukan, produktivitas pohon mangga akan meningkat walaupun tidak secara langsung. Namun perawatan pohon seringkali tidak dilakukan jika produktivitas pohon mangga dianggap masih baik (Loop B8).

Perilaku petani yang seringkali menggunakan ZPT dan pestisida secara berlebihan ini tentu akan berpengaruh secara positif terhadap biaya perawatan pohon. Semakin sering ZPT dan pestisida digunakan, semakin besar pula biaya perawatan yang harus dikeluarkan oleh petani. Kenaikkan biaya perawatan ini kemudian akan berdampak pada kenaikkan biaya produksi yang harus dikeluarkan oleh petani. Besaran biaya produksi kemudian akan berpengaruh pada pendapatan secara negatif(Loop B9).

Dalam penggambaran CLD, terdapat leverage point atau titik ungkit yang menjadi poros dari keseluruhan loop tersebut. Leverage point adalah suatu titik dari sebuah proses, yang jika dilakukan perubahan terhadap titik tersebut, maka akan mengakibatkan perubahan pada sebagian besar atau keseluruhan sistem.

Variabel perawatan pohon menjadi leverage point dari ke-20 variabel yang saling berkaitan dalam CLD Petani pada Gambar 1. Variabel perawatan pohon ditentukan sebagai leverage point karena memiliki pengaruh terbanyak terhadap keseluruhan sistem dibanding dengan variabel lain. Variabel perawatan pohon membentuk 13 feedback loops, dengan feedback loop terpanjang terdiri dari 10 variabel yaitu perawatan pohon, daya tahan pohon, serangan OPT, produktivitas pohon mangga, produksi mangga, ketersediaan mangga, mangga berkualitas, harga mangga, permintaa, penerimaan, dan pendapatan.

\section{KESIMPULAN DAN SARAN}

Intensitas curah hujan, yang mengindikasikan terjadinya perubahan iklim, mempengaruhi produktivitas mangga secara negatif. Semakin tinggi curah hujan akan menyebabkan semakin rendah produktivitas mangga. Hal ini menyebabkan munculnya perilaku adaptasi petani mangga guna meminimalisi resiko akibat perubahan iklim. 
Perilaku adaptasi petani mangga di Kecamatan Panyingkiran Kabupaten Majalengka dipengaruhi oleh faktorfaktor yang saling terkoneksi satu sama lain dalam hubungan sebab-akibat, yang selanjutnya disebut sebagai variabel. Pada bahasan ini terdapat 20 variabel yang membentuk causal loop diagram, yaitu curah hujan, luas lahan, jumlah pohon, produksi mangga, ketersediaan mangga, mangga berkualitas, harga mangga, permintaan, penerimaan, pendapatan, alokasi uang untuk pembelian sarana produksi dan input pertanian, sarana produksi dan input pertanian, produktivitas pohon mangga, penggunaan ZPT, daya tahan pohon, serangan OPT, penggunaan pestisida, perawatan pohon, biaya perawatan, dan biaya produksi.

Dari keseluruhan variabel tersebut, perawatan pohon ditentukan sebagai leverage point karena memiliki pengaruh terbanyak terhadap keseluruhan sistem dibanding dengan variabel lain.

\section{DAFTAR PUSTAKA}

Adger, W. Neil et. al. 2003. Adaptation to Climate Change in The Developing World. Progress in Development Studies, 3 (3).

Babara, Martan. 2014. Analisis kontroversi pembangunan pembangkit listrik tenaga sampah di Kota Bandung sebuah pendekatan systems thinking. Tesis. Program Magister Studi
Pembangunan, Sekolah Arsitektur, Perencanaan, dan Pengembangan Kebijakan, Institut Teknologi Bandung.
Badan
Penelitian
dan

Pengembangan Pertanian, Kementerian

Pertanian. 2011. Pedoman Umum Adaptasi Perubahan Iklim Sektor Pertanian.

Badan Perencanaan Pembangunan Nasional. 2012. National Action Plan for Climate Change Adaptation (RAN-API). Jakarta: Bappenas.

Badan Pusat Statistik. 2018. Produksi Tanaman Buah-buahan Indonesia Tahun 2010-2016.

Badan Pusat Statistik. 2017. Kabupaten Majalengka Dalam Angka.

Boer, Rizaldi dan Suharnoto Y., 2012. Climate change and its impact on Indonesia's food crop sector. Sixth Executive Forum on Natural Resource Management: water and food in a changing environment on. P. 11-13.

Direktorat Jenderal Hortikultura Kementerian Pertanian. 2014. Luas Panen Mangga Meurut Provinsi, 2012-2016.

Handayani, I Gusti Ayu Ketut Rachmi et. al. 2015. Guarantee Access to Information of Climate Change on Water Resources Based on National Plan For Climate Change Adaptation in Indonesia. International Journal of Business, Economics and Law, 7 (4), p. 114-ISSN 2289-1552.

Pracaya. 2011. Bertanam Mangga. Depok: Penebar Swadaya

Prawaka, Fanny. 2016. Analisis data curah hujan yang hilang dengan menggunakan metode normal ratio, inversed square distance, dan rata-rata aljabar (Studi kasus curah hujan beberapa staiun hujan daerah Bandar Lampung). Skripsi. Fakultas Teknik Universitas Lampung.

Ramadhani, Widyarina dan Elly Rasmikayati. 2017. Dinamika agribisnis petani mangga di Kecamatan Panyingkiran Kabupaten Majalengka 
Provinsi Jawa Barat. Jurnal Ilmiah Mahasiswa AGROINFO GALUH. 4 (3) hal. 498.

Sterman, John D. 2000. Business dynamic: systems thinking and modelling for a complex world. United States of America: McGraw-Hill Companies, Inc.

Sugihardjo, Eny Lestari, dan Agung Wibowo. 2012. Strategi bertahan dan strategi adaptasi petani samin terhadap dunia luar. SEPA. 8 (2) hlm. 145-ISSN: 1829-9946.

Surmaini, Elza, Eleonora Runtunuwu dan Irsal Las. 2011. Upaya sektor pertanian dalam menghadapi perubahan iklim. Jurnal Penelitian dan Pengembangan Pertanian, 30 (1), p. 1-EISSN: 2541-0822. Akreditasi LIPI: No. 697/AU3/P2MI-LIPI/7/2015.
Tjasyono, Bayong. 2004. Klimatologi / Bayongg Tjasyono. Bandung: Penerbit ITB.

Wicaksana, Gede Ariahastha. 2015. Pemodelan hidrologi daerah aliran sungai tukad pakerisan dengan software HECHMS. Tesis. Jurusun Teknik Sipil, Fakultas Teknik, Universitas Udayana.

Sugiyono. 2017. Metode Penelitian Kuantitatif, Kualitatif, dan $R \& D$. Bandung: Alfabeta. 